\title{
EL CUERPO COMO VALOR EDUCATIVO: LA POSTMODERNIDAD FRENTE AL CRISTIANISMO
}

\author{
The body as an educative value: \\ the postmodernity opposing the christianity
}

\section{Enrique GERVILLA CASTILLO}

Universidad de Granada. Departamento de Pedagogía. Facultad de Ciencias de la Educación. Campus Universitario "La Cartuja" 18071 Granada.

Fecha de aceptación definitiva: marzo de 2000.

BIBLID [(1130-3743) 11, 1999, 101-125]

RESUMEN

El cuerpo ha recibido diversos sentidos y valoraciones a través de la historia de la filosofía. En este artículo se analizan los valores del cuerpo desde el cristianismo y la postmodernidad, ambos vigentes en la actualidad con orientaciones antagónicas. La educación, que siempre se fundamenta en el valor/valoración, ha de optar por uno u otro modelo: el de los catecismos o el de los medios de comunicación.

SUMMARY

The body has received several senses and valuations throughout the history of the filosofy. In this article, it is analized the values of the body from the Christianity and the postmodernity, both prevailing nowadays with antagonistic positions. The education, wich is always based on the value/valuation, must choose one or another model: the catecisms one or the reporting mediums pattern. 


\section{INTRODUCCIÓN: EL CUERPO, TEMA DE HOY Y DE SIEMPRE}

El cuerpo ha sido, desde siempre, un tema de especial interés. Pregunta y problema que ha recibido, a través de la historia de la filosofía, variadas respuestas y soluciones, cuya herencia milenaria nos ofrece hoy múltiples caras o rostros de este singular animal, de múltiples calificativos: "animal racional", animal político", animal simbólico", "animal que ríe", "animal que habla".., pero siempre animal.

Hoy, en todos los ámbitos de la educación -formal, no formal e informal-continúa siendo un valor de interés especial. Baste recordar: la creación de la especialidad de Educación Física en los estudios de Magisterio (LOGSE), la reciente creación de las Facultades de la Actividad Física y el Deporte, la proliferación de gimnasios, de salones y centros de belleza, los medios de comunicación social: TV con sus "estudiados" presentadores/as, revistas, literatura, películas, canciones, etc.

El cuerpo, sin embargo, en todos estos ámbitos educativos, siendo el mismo cuerpo, no es lo mismo. De diverso modo, y desde sentidos distintos, se ocupan del cuerpo el profesor de Educación física, el cirujano, el esteticista, el deportista, la pornografía o cualquier Instituto de salud... Por lo que se hace necesario, para una comunicación precisa, determinar los significantes y sentidos del mismo.

Nuestro propósito aquí es filosófico y educativo. Nos proponemos clarificar los diversos sentidos y también valores (sentidos apetecibles) del cuerpo ${ }^{1}$ en dos ámbitos concretos, ambos vigentes con fuerza en nuestra sociedad: el cristianismo y la postmodernidad, ante los cuales la educación ha de optar. Más aún, pretendemos mostrar el conflicto cuerpo-educación entre la postmodernidad y el cristianismo al valorar el sentido del cuerpo de modo antagónico uno y otro.

Nadie actualmente duda de la importancia del cuerpo, ni de su valor educativo. La polémica no se centra en el valor del cuerpo, sino en qué cuerpo, esto es, el sentido, o mejor, los sentidos -en plural-que se le otorgan a éste. Desde la antigua concepción platónica del cuerpo "cárcel del alma", hasta la actual "Darle a tu cuerpo alegría Macarena", los distintos sentidos y valoraciones del cuerpo han sido plurales, como manifiesta la Historia de la Filosofía y de la educación ${ }^{2}$.

Las preguntas, a las que pretendemos dar respuesta, son las siguientes: ¿Qué queremos decir cuando decimos "cuerpo" en la concepción cristiana y postmoderna? ¿Qué hacer, en la educación, ante el antagonismo de una y otra valoración?

1. Siguiendo al profesor Fullat, entendemos aquí el valor como el sentido del ser. FULLAT, O. "Cartaprólogo: El valor; mejor el bien". En GERVILLA, E. (1998): Axiología Educativa. TAT, Granada, p. 5. El profesor Barrios, por su parte, sostiene: "La realidad del valor es un aspecto del bien. El bien es el depositario del valor, siendo éste, concretamente, la bondad de lo bueno. Entiendo por bien un aspecto del ser, concretamente la capacidad que éste reviste de provocar una apetición" BARRIO, J. M. (1998): Elementos de antropología pedagógica. Rialp, Madrid, p. 191.

2. Sobre estos sentidos y valoraciones, Vd. GERVILLA, E. (1999): Valores del cuerpo educando. Antropología del cuerpo y educación. Herder, Barcelona. Cuerpo cárcel del alma, cuerpo carne o materia viva, cuerpo dinámico, cuerpo estético, cuerpo placer, cuerpo ético, cuerpo afectivo-social, cuerpo ecológico, cuerpo instrumental, cuerpo trascendente/religioso. 


\section{El VALOR DEL CUERPO EN EL CRISTIANISMO}

En opinión de Julián Marías, el cristianismo marca la división más profunda en la historia de la filosofía, pues, al modificar los supuestos metafísicos sobre los que el hombre se mueve, ha cambiado también la situación desde la cual tiene que filosofar. En efecto, la filosofía cristiana aporta una idea totalmente nueva que da sentido a la existencia del mundo y del hombre: la creación. "Al principio creó Dios el cielo y la tierra. De esta frase del Génesis arranca la filosofía moderna ${ }^{3}$.

"Tenemos de una parte a Dios, el verdadero ser, creador; por otra parte, el ser creado, la criatura, cuyo ser es recibido. La verdad religiosa de la creación es quien obliga a interpretar ese ser, y plantea el problema filosófico del ser creador y del creado, de Dios y de la criatura" ${ }^{4}$.

Desde tales presupuestos, el sentido del cuerpo es interpretado desde un fundamento concreto, aunque, a veces, con idéntica o parecida formulación filosófica. Así, el cristianismo, en ciertos momentos históricos, incorporó a su doctrina buena parte del concepto hombre expresado en la filosofía greco-romana: un compuesto de cuerpo material y alma espiritual; en otros, sin embargo, optó por un monismo antropológico, si bien, siempre aportando el sentido peculiar de relación Dios-criatura.

\subsection{El cuerpo, valor integral de la persona, según el pensamiento bíblico}

Toda la filosofía cristiana sobre el cuerpo, predominante en la patrística y durante la Edad Media, arranca de la idea bíblica de hombre. Su antropología -al margen del valor añadido de la fe, del cual obviamente prescindimos- ha condicionado durante siglos toda la filosofía y la cultura cristiana. Su importancia, por tanto, es grande, ya que su influencia se extiende durante el período filosófico de la Patrística hasta la Edad Media, en el que la filosofía se encontraba al servicio de la fe: "Philosophia ancilla theologiae». Pero su significado no se agota aquí, pues buena parte del valor que nosotros hoy damos al cuerpo, y la educación que sobre él hemos recibido, tiene en el pensamiento cristiano sus raíces. No olvidemos que la Biblia es el libro más leído a nivel mundial.

En la concepción antropológica bíblica confluyen tres términos hebreos de uso frecuente en la literatura del A.T., especialmente en el Génesis, y de gran interés, por cuanto el uso de uno u otro manifiesta el valor predominante -siempre unitario- de persona más corporal o más espiritual: "basar", "nefes", "ruah" ${ }^{5}$.

3. MARÍAS, J. (1964) Historia de la Filosofia, Revista de Occidente, Madrid, p. 103.

4. Id., p. 104.

5. RUIZ DE LA PEÑA, J. L. (1988): Imagen de Dios. Antropología teológica fundamental. Sal Terrae, Santander, p. 20 ss. 
El vocablo "basar" originariamente significó "carne" de cualquier ser vivo, bien sea animal u hombre. Este uso común de "basar" subraya el substrato biológico común entre los seres vivientes. Pero, "basar" puede, además, poseer otros sentidos: parentesco, acentuando la dimensión social del hombre, por lo que la carne del otro es, en cierto sentido, la propia carne ${ }^{6}$, y también debilidad física y/o moral. De aquí que el vocablo "basar" nunca se aplique a Yahvé.

"Nefes", en sus orígenes, significó garganta, el órgano de la respiración y la respiración misma. De aquí su sentido vital común a hombres y animales, que referido a los humanos hoy podríamos traducir por personalidad. Así, "Basar" y "nefes" se utilizan indistintamente para denotar el hombre entero. No se trata del binomio cuerpo-alma, pues cada uno de los términos es expresión de la totalidad de lo humano: todo hombre es -y no tiene- "basar"; y todo hombres es -y no tiene"nefes". Todo el hombre es una unidad psicosomática, cuerpo animado o alma encarnada.

"Ruah" significó viento, brisa, pero para referirse al espíritu de Yahvé. Se trata, por tanto -a diferencia de "nefes"- no de un aliento inmanente al ser vivo, sino de una fuerza creadora, de un don divino. Es un vocablo teoantropocéntrico con el que se expresa la apertura del hombre hacia la divinidad, su dimensión trascendente.

La contraposición "basar"-nruah" no reproduce la oposición dualista entre lo material y lo inmaterial, sino más bien la dialéctica entre la finitud y limitación de la criatura y el poder ilimitado y omnipotente de Dios creador. El hombre en cuanto ser-en-sí es "nefes" y "basar", destinado a la caducidad y a la impotencia, pero no es una entidad clausurada en sí, sino abierto, capaz de sostener una relación horizontal, con sus semejantes, y vertical, con Dios.

Este triple significado o valoración del cuerpo-persona, que expresan los términos "basar", "nefes" y "ruah", se encuentra presente, de modo gráfico, en los mismos orígenes del ser humano. La fuente yavística ${ }^{7}$, la más antigua (s. IX a Jc.), nos relata la creación del hombre del siguiente modo: "Entonces Yabvéb Dios formó al bombre con polvo del suelo, e insufló en sus narices aliento de vida, y resultó el bombre un ser viviente" (Gen. 2, 7).

El verbo "formar" que designa el trabajo del alfarero. Este antropomorfismo de un Dios alfarero, modelando de barro una figura humana, subraya el carácter terreno del hombre, su ligazón a la materia, su caducidad. Habiendo sido formado de barro su constitución adolece de la misma fragilidad que caracteriza la vasija. Y lo que es más importante aún: su ser se encuentra ligado a la misma relación de dependencia del creador que la vasija del alfarero que la modeló ${ }^{8}$.

6. Gen. 2,23-24: Hombre y mujer serán una sola carne.

7. Las dos fuentes se denominan Yahvista y Elohísta. El Yahvista en el relato de la creación usa el nombre de Yahvéh; la Eloísta, designa de Dios con el nombre de Elohim. El Yahivsta fue escrito en el siglo IX en Judá, el Elohista, algo más tarde en Judá. (Biblia de Jerusalén, Desclée de Brouwer, 1975, p. 6).

8. Es ésta una idea frecuente en el A.T. El bombre está en manos de Dios como el barro en las manos del alfarero: Jr. 18,1-6; Sal. 103,14; Is. 45,9; Rom. 9, 20. 
A esta materia "polvo", Dios insufla el "aliento" -vocablo sinónimo de "nefes"-. El resultado de esta doble operación es el nacimiento de un ser viviente: hombre y no animal, pues los animales, aunque también son formados del polvo de la tierra, no reciben el "nefes", falta este "insuflar" de Dios en ellos el aliento". Sólo el hombre establece esta relación directa con el creador. De aquí que, al final de la vida, el hombre, al exhalar el aliento, vuelva nuevamente al polvo, a su origen. Todos han salido del polvo y todos vuelven al polvo.

La persona, pues, consta de dos elementos: polvo y aliento, pero lo que Dios crea no son dos elementos, al estilo platónico cuerpo-alma, sino un sólo ser, no crea el cuerpo, sino el hombre. El dualismo antropológico no existe en la mentalidad hebrea.

Esta armonía y bondad del cuerpo quedaron rotas tras la desobediencia de la primera pareja de la humanidad. Según el capítulo $3^{\circ}$ del Génesis, Adán y Eva, al querer ser como dioses, perdieron parte de los dones que Dios les otorgó, y, en consecuencia, su ser personal quedó sustancialmente afectado. A partir de esta ruptura su estado inicial quedó modificado. Ahora nos encontramos con un hombre "caído". El cuerpo, y con él todo el ser humano dado su sentir unitario, quedó inclinado hacia el mal, alejado del Creador, sometido a la muerte y a la concupiscencia ${ }^{10}$.

Los Escritos Sinópticos heredarán este monismo hebreo. El vocablo cuerpo o alma aluden a la persona en su totalidad. Tras un análisis de su contenido, concluye el profesor Ruiz de la Peña:

"No hemos descubierto ningún texto donde aparezca inequívocamente el esquema "Sôma-psyché" en su acepción griega, componentes distintos del hombre entero. En los contados lugares que utilizan a la vez los dos términos, éstos revisten un significado diverso del que le otorga el esquema dicotómico helenista. Cuando "psyché" se emplea en solitario, tras el término reconocemos fácilmente el hebreo "nefes". Algo semejante ocurre con "sôma" usado aisladamente, que evoca el significado de "basar", al que traduce corrientemente en la versión de los LXX" "11.

En síntesis, pues, el cuerpo (= persona), es siempre un valor en sí al participar de la bondad de su Creador. Sin embargo, desde la "caída" (pecado original), cabe la posibilidad de ser vivido negativamente. De aquí que, ante su valoración religiosa,

9. Gen. 2.19-20.

10. LADAIRA, L. F. (1993): Teologia del pecado original y de la gracia. B.A.C., p. 44 y ss.

11. Imagen de Dios. Antropología teológica fundamental, o. c., p. 70.

Las valoraciones sobre el cuerpo de Pablo de Tarso, ya en el siglo I, se insertan antropológicamente en el mismo sentido hebreo, si bien incorporando los influjos culturales del momento. Una primera interpretación hermenéutica constata en Pablo la existencia de una oposición entre la carne y el espíritu, semejante a la interpretación dualista griega (Gál. 5, 16-17). Una segunda interpretación sostiene que tal oposición no son partes diferentes, ni opuestas del ser humano, sino más bien dos distintos aspectos de un mismo conjunto o realidad. La triple antítesis del pensamiento griego: materia-forma / múltiple-uno / cuerpo-alma resulta ajena al pensamiento hebreo y también al paulino TAMAYO, J. J. (1993): Escatología cristiana, Verbo Divino, Estella, Navarra, p. 205. 
ciertos vocablos de sentido generalmente negativo no lo sean en este contexto bíblico. Así, por ejemplo "debilidad", "fragilidad" o "mortalidad", no expresan más que la relación de la criatura con su Creador, la esencia misma del ser personal.

A partir de estos presupuestos bíblicos, la patrística ${ }^{12}$ hará presente las dos valoraciones del cuerpo reinantes en los siglos precedentes en el pensamiento hebreo y griego: la bondad del cuerpo (tradición antioquena: Tertuliano, S. Ireneo...) y la maldad del mismo por ser impedimento del alma (tradición alejandrina: Lactancio, S. Agustín...).

La filosofía medieval heredó el problema de la patrística, si bien ahora el punto central de interés será escatológico. ¿Qué es lo que se salva? ¿Tan sólo una parte o la totalidad? Los medievales oscilarán entre el platonismo y el aristotelismo, pues si la doctrina platónica del alma ponía en peligro la unidad sustancial del hombre, la doctrina aristotélica de la unidad sustancial cuestionaba la espiritualidad e inmortalidad del alma. O se situaba al alma tan cerca de la divinidad que se separaba del cuerpo, o se la concebía tan interna a la materia-cuerpo que se la hacía perecer con éste. Estaba reservado a Santo Tomas la solución a este problema, o al menos otra solución al mismo, al sostener que el cuerpo es la materia informada por el alma. El alma es así la forma sustancial del cuerpo, una forma que posee y confiere sustancialidad.

\subsection{El valor del cuerpo según los catecismos de la Iglesia católica}

La axiología patrística sobre el cuerpo dejaba abierto el camino a esta doble opción: bondad o maldad, susceptible posteriormente de múltiples concreciones y matizaciones, pues, como acabamos de indicar, unos vieron el pensamiento cristiano influenciado por la tradición platónica y neoplatónica y, en consecuencia, la materia-cuerpo bajo una especie de "mal"; otros, sin embargo, bajo la visión de la filosofía hebrea o más aristotélica, aceptaron la bondad del cuerpo humano, acentuando la transformación o transfiguración final del mismo.

De hecho, los catecismos, textos de educación religiosa en los que se educaron las generaciones precedentes y gran parte de la actual población española, optaron por el sentido más negativo del cuerpo: Platón y S. Agustín ganaron la batalla al monismo hebreo e incluso a Santo Tomás. Prueba de ello son los catecismo de Gaspar Astete y de Jerónimo Ripalda, ambos escritos en el siglo XVI, textos de nuestros padres y abuelos. Su popularidad y divulgación llegó a ser tal en España e Hispanoamérica que, a comienzos del siglo XX, habían alcanzado el millar de ediciones ${ }^{13}$.

12. La patrística alcanza su madurez en el siglo IV, cuando las herejías lograron su mayor agudeza. Dominó la cultura cristiana hasta el advenimiento de la Escolástica, en el siglo IX.

13. COLOM, J. (1971) Manual de catequesis, vol. I, p. 65, Herder, Barcelona. Sobre la evolución de estos catecismos, Vid. RESINES, L. (1997): La catequesis en España. BAC, Madrid. 
En España fueron durante siglos los textos oficiales de educación religiosa hasta el año 1957, optando las provincias del Norte por Astete, mientras que las del Sur lo hacían por Ripalda. E incluso habiendo perdido su oficialidad en el campo de la educación, nuevas ediciones de uno y otro han sucedido ${ }^{14}$.

En ambos catecismos se expone y justifica un acentuado dualismo antropológico, de concepción platónico-agustiniana. El hombre se define como un ser racional, creado por Dios, compuesto de dos elementos: cuerpo y alma, en abierta pugna, en la cual el alma debe vencer al cuerpo. Éste, junto al demonio y a la carne, son los enemigos del alma. Al cuerpo le dotó Dios de cinco sentidos (ver, oír, gustar, oler y tocar) y al alma de tres potencias (memoria, entendimiento y voluntad). Todo el ser del hombre, cuerpo y alma, sólo adquiere sentido si cumple la finalidad para la que fue creado: servir a Dios y llegar a la vida eterna.

El cuerpo no es más que la materia corruptible, que hay que dominar mediante la ascesis, el sacrificio y la mortificación, hasta alcanzar el triunfo: la salvación eterna del alma, y al final del mundo su propia resurrección. El ámbito escolar reflejaría esta concepción del cuerpo en las lecturas, modos de vestir, separación de sexos, educación física, etc.

Tal valoración negativa del cuerpo, sobre todo el contenido sexual, tuvo también fuertes repercusiones fuera del ámbito escolar: la censura en los medios de comunicación, modos de diversión, concepto de las relaciones prematrimoniales, matrimonio, etc. Recordemos al respecto la Encíclica de Pío IX «Divini Illius Magistri,, sobre la educación cristiana, publicada el 21 de diciembre de 1929, en la que expresamente se condena la coeducación, por ser un método “erróneo y pernicioso a la educación cristiana", e igualmente aquella educación que "con feo nombre promueven la llamada educación sexual " ${ }^{15}$. Más aún, toda la cultura y las costumbres quedarán afectadas de este antivalor cuerpo: fiestas, modos de vestir, pintura, escultura, etc. No es éste el momento de detallar el sentido de tales repercusiones ya investigadas, por otra parte, en el período del Nacional Catolicismo en mi trabajo de tesis doctoral ${ }^{16}$.

De este modo, se extiende la idea de que el cuerpo es mortal y el alma inmortal, desapareciendo del horizonte el valor bíblico de "vida". Se generaliza la idea de "Salvar el alma" tan lejana a la escatología bíblica, llegándose al desprecio del mundo y a un espiritualismo desencarnado que nada tiene que ver con la antropología bíblica ${ }^{17}$.

14. La editorial Magisterio Español en el 1969 realizaba una nueva edición del catecismo del $P$. ASTETE, haciendo constar su intención, no de sustituir al Catecismo Escolar, "sino el deseo frecuentemente expresado por muchas personas, de ponerlo en manos de aquéllas que, en sus años de infancia, bubieron de estudiarlo como libro de texto, así como muchos estudiosos que desean tenerlo como libro de consulta para sus estudios en las obras maestras de la literatura religiosa". Otras ediciones han sido realizadas por Alberto Gómez en Granada (1979) y por el dominico Arturo Alonso.

15. PÍO IX (1930): La educación cristiana. Editorial Librería Religiosa, Barcelona, pp 81 y 86.

16. GERVILLA, E. (1990): La Escuela del Nacional Catolicismo. Ideología y Educación religiosa. Impredisur, Granada.

17. TAMAYO ACOSTA, J.J., o. c., p. 219. Uno de los ejemplos más puros del dualismo platónico unido a la espiritualidad cristiana lo encontramos en "La imitación de Cristo" de T. Kempis. En este famoso libro de espiritualidad podemos leer lo siguiente: 
Los catecismos posteriores sostuvieron el mismo dualismo antropológico cuerpo-alma, si bien acentuando el reflejo de la imagen de Dios. En consecuencia, el cuerpo ya no aparece como enemigo del alma, es más, se afirma que es «templo del Espíritu Santo", recogiendo el valor paulino del cuerpo. Así, en el Catecismo. Texto Nacional. Tercer grado, año 1962, leemos:

"¿Qué es el hombre? El hombre es un ser racional y libre, compuesto de cuerpo y alma, creado por Dios a su imagen y semejanza" ( $\left.n^{\circ} 45\right)$.

"¿Tenemos los cristianos algún motivo especial para amar la pureza? Los cristianos tenemos un motivo especial para amar la pureza, porque somos por la gracia miembros de Cristo y templos del Espíritu Santo" ( $\mathrm{n}^{\circ} 145$ ).

Hemos de esperar al año 1992 para que expresamente se afirme el valor del cuerpo, pero también su permanente tensión entre la carne y el espíritu. Así en el Catecismo de la Iglesia Católica, se afirma "El cuerpo del hombre participa de la dignidad de 'imagen de Dios': es cuerpo bumano precisamente porque está animado por el alma espiritual, y es toda la persona bumana la que está destinada a ser Templo del Espiritu” ( $n^{\circ}$ 364). Ello no obsta para que en él se dé una permanente tensión:

"En el hombre, porque es un ser compuesto de espíritu y cuerpo, existe cierta tensión, y se desarrolla una lucha de tendencias entre el "espíritu" y la "carne". Pero en realidad esta lucha pertenece a la herencia del pecado. Es una consecuencia de él, y, al mismo tiempo, confirma su existencia. Forma parte de la experiencia cotidiana del combate espiritual" ( $\mathrm{n}^{\circ}$ 2516).

Desde esta nueva visión, la Iglesia católica actual se aleja de la valoración negativa del cuerpo de los catecismos precedentes, y si bien acepta el cuerpo como valor, siempre será un "valor de medio" o relativo, por lo que se opone a cualquier culto o sobrevaloración del cuerpo como puede ser la excesiva perfección física o el éxito deportivo ( $\mathrm{n}$-2289), la gula, la masturbación, homosexualidad, pornografía, prostitución, relaciones prematrimoniales, etc. ( $\mathrm{n}^{\circ} 2351$ y ss.): "El placer sexual es moralmente desordenado cuando es buscado por sí mismo, separado de las finalidades de procreación y unión" ( $\left.\mathrm{n}^{\mathrm{o}} 2351\right)$. "La masturbación es un acto intrínseca y gravemente desordenado" ( $\left.\mathrm{n}^{\mathrm{o}} 2352\right)$.

"iOh, si no tuviéramos necesidad de comer, de beber ni de dormir! ¡Si pudiéramos estar alabando siempre a Dios y servirle solamente con un continuo servicio espiritual! Seriamos más felices, mucbo más felices que abora, entregados como estamos a la vida de los sentidos por necesidad. ¡Si no tuviéramos ninguna necesidad corporal, sino solamente espirituales; iQué felicidad seria el santificarlas! Y esta felicidad ¡cuán raramente la experimentamos!”.

Esta forma espiritualista de vida, al margen o contra el cuerpo, tiene también hoy su prolongación en ciertos modos de vida cristiana de nuestro tiempo, cual es el Opus Dei. Su fundador escribía en el libro "Camino": "Si sabes que tu cuerpo es tu enemigo, y enemigo de la gloria de Dios, al serlo de tu santificación, ¿por qué le tratas con tanta blandura?" ( $n^{\circ} 2227$ ). 
Es necesario, pues, para la integridad de la persona la virtud de la castidad que "implica un aprendizaje del dominio de sí, que es una pedagogía de la libertad bumana. La alternativa es clara: o el hombre controla sus pasiones y obtiene la paz, o se deja dominar por ellas y se hace desgraciado" ( $\mathrm{n}^{\circ}$ 2339). Ello se adquiere mediante el conocimiento de sí, la ascesis, la práctica de las virtudes morales, la mortificación, la templanza, etc., por cuanto "la castidad representa una tarea eminentemente personal, , pero no debemos olvidar la influencia de la sociedad y de la cultura en este sentido, pues la castidad implica también un esfuerzo cultural, pues el desarrollo de la persona bumana y el crecimiento de la sociedad misma está mutuamente condicionados" 18 .

Esta visión cristiana del cuerpo contrasta fuertemente con otra visión o valoración del cuerpo muy poderosa también entre nosotros: la postmodernidad.

\section{EL VALOR DEL CUERPO EN LA POSTMODERNIDAD}

"La noción de postmodernidad no es clara" ${ }^{19}$. Se trata de un nuevo "ethos", sensibilidad, talante, condición o praxis de extensión e intensidad diversas, en la que es posible múltiples clasificaciones y adjetivos: postmodernismo de "resistencia" y de "reacción"; postmodernistas "escépticos" y "afirmativos" ${ }^{20}$. Esta "nueva constelación" de autores, a veces más yuxtapuestos que integrados en sus críticas a la modernidad podrían ser coincidentes, en algún sentido, en lo siguiente ${ }^{21}$ : 1 - $-E l$ desencanto y debilidad de la razón que, desde el Renacimiento y la Ilustración, lentamente se ha convertido en inseguridad, desconfianza, decepciones y desengaños. 2.- La pérdida del fundamento que ha ocasionado la fragmentación y el nacimiento de múltiples fundamentos, terminando con los grandes principios de la modernidad. 3.- El fin de las utopias o la incredulidad de los grandes relatos (metarrelatos) que liberan al hombre del sentido o proyecto único y totalizante. 4.- La fragmentación moral: individualismo bedonista y narcisista, por cuanto perdido todo fundamento -del ser, de la razón, de la historia- no queda más que fragmentación existencial. 5.- Un pluralismo de valores ante la carencia de valores absolutos y la exaltación de la vida bajo «Dionisios".

18. Cita que el Catecismo toma del Concilio Vaticano II (GS 25, 1).

19. LIPOVETSKY, G. (1990): La era del vacio. Ensayos sobre el individualismo contemporáneo. Anagrama, Barcelona, p. 79.

20. ROSENAU, P. M. (1991): Postmodernism and the Social Sciences: Insights, Inroads and Intmsions. Priceton, Univ. Press. Entre los "escépticos" -en opinión de Rubio Carracedo- hay que situar a Foucault y Braudillard; entre los "afirmativos" (llamados por N. Rengger "epicúreos") a Rorty y Lyotard. BUBIO CARRACEDO, J. Educación moral, postmodernidad y democracia, Trotta, Madrid, pp. 92-93.

21. GERVILLA, E. (1997): Postmodernidad y educación. Valores y cultura de los jóvenes. Dykinson, Madrid. 


\subsection{Los valores del cuerpo según Lipovetsky}

Dados los límites imprecisos de la "postmodernidad", se hace difícil dar una definición de ésta y, en consecuencia, difícil también indicar con precisión la valoración dada al cuerpo. De aquí que, por precisión y brevedad, nos hayamos centrado en Lipovetski -filósofo que reflexiona sobre el cuerpo-, así como en la presencia o prolongación de tal visión en nuestra sociedad. De este modo aceptamos una doble división de la postmodernidad: la de los intelectuales y la postmodernidad de la calle o popular.

Tres obras de Lipovetsky han centrado nuestra atención, cuyos títulos y subtítulos, ya desde el comienzo, son altamente significativos: 1.- "La era del vacio. (Ensayos sobre el individualismo contemporáneo"). 2.- "El imperio de lo efimero. (La moda y su destino en las sociedades modernas)". 3.- "El crepúsculo del deber. (La ética indolora de los nuevos tiempos democráticos"). Estas tres obras son coincidentes en sostener el alto valor del cuerpo en la jerarquía axiológica de la postmodernidad. Sus solicitudes y cuidados son hoy de tal importancia que constituye "un verdadero objeto de culto" 22 . Un objeto de culto valorado en múltiples sentidos apetecibles o valoraciones que -siguiendo el pensamiento del profesor de filosofía de Grenoble- lo hemos orientado dando al cuerpo los siguientes calificativos:

\subsubsection{El cuerpo sex-ducción}

Sexducción (con $\mathrm{x}$ ) denomina Lipovetsky a la personalización del cuerpo bajo la égida del sexo. Cuerpo y sexo se vuelven instrumentos de subjetivación-responsabilización. "Su cuerpo es usted, existe para cuidarlo, amarlo, exhibirlo, nada que ver con la máquina. La seducción amplía el ser-sujeto dando una dignidad e integridad al cuerpo antes oculto: nudismo, senos desnudos son los signos espectaculares de esa mutación por la que el cuerpo se convierte en persona "23.

Se trata de un sexo no sólo separado del amor, sino también separado del sentimiento. En expresión de Chr. Lasch: "the fligh from feeling" (la huida ante el sentimiento), una separación entre el sexo y el sentimiento ${ }^{24}$. Ello supone una liberación de todo condicionamiento para la práctica del placer sexual. Tal liberación apunta a un mismo fin: levantar barreras contra las emociones y dejar a un lado las intensidades afectivas. Es el fin de la cultura sentimental y el nacimiento de una cultura "COol" en la que cada cual vive en su bunker de indiferencia, a salvo de sus pasiones y de las de los otros ${ }^{25}$.

22. LIPOVETSKY, G. (1990): La era del vacío. Ensayos sobre el individualismo contemporáneo. Anagrama, Barcelona, p. 60

23. Ibíd., p. 30.

24. Ibíd., 76.

25. Ibíd., p. 77. 
No se trata de una huida o rechazo del sentimiento, sino de que éste sea condición necesaria para la práctica de las relaciones sexuales. Es toda una liberación, pues destruye el orden arcaico de la ley, la prohibición, la censura, la represión «en beneficio de un verlo-todo, hacerlo-todo, decirlo-todo que define el trabajo mismo de la seducción (...). Aquí todo está permitido, hay que ir siempre más lejos, buscar dispositivos inauditos, buenas combinaciones en una libre disposición del cuerpo $^{26}$. Toda inmovilidad y estabilidad ha de desaparecer en provecho de la iniciativa y experimentación. No se trata, por tanto, de un proceso de deshumanización, sino de un proceso de personalización. Las personas siguen buscando la emoción, pero ésta no siempre es posible, por lo que el drama es aún más profundo. "Hombres y mujeres siguen aspirando a la intensidad emocional de las relaciones privilegiadas (quizás nunca hubo una tal 'demanda' afectiva como en estos tiempos de deserción generalizada), pero cuanto más fuerte es la espera, más escaso se hace el milagro fusional y en cualquier caso más breve. Cuanto más la ciudad desarrolla posibilidades de encuentro, más solos se encuentran los individuos (...). En todas partes encontramos la soledad, el vacío, la dificultad de sentir, de ser transportado fuera de sí; de ahí la huida hacia adelante en las experiencias que no hace más que traducir esa búsqueda de una experiencia emocional fuerte ${ }^{27}$.

Hoy la sex-ducción es generalizada. La tecnología y los medios de comunicación, que todo lo invaden, han unido el objeto correspondiente con el sexo en el mismo ciclo ilimitado de manipulación. El cine, las canciones, la TV. ${ }^{28}$, el mundo de la cultura y del consumismo han democratizado el sexo y el hedonismo, han privilegiado "los impulsos más bajos antes que los más nobles" 29 .

El consumo, en un ansia de liberación de convenciones rígidas, trata de reducir las diferencias entre sexos y generaciones. Lo masculino y lo femenino se mezclan, pierden sus características diferenciadas de antes; la homosexualidad de masas empieza a no ser considerada como perversión, se admiten todas las sexualidades o casi y forman combinaciones inéditas; el comportamiento de los jóvenes y de los no tan jóvenes tiende a acercarse: en unos pocos decenios éstos se han adaptado a gran velocidad al culto de la juventud, a la edad 'psi', a la educación permisiva, al divorcio, a los atuendos informales, a los pechos desnudos, a los juegos y deportes, a la ética hedonista ${ }^{30}$. Se trata, en definitiva, de una legitimación de todos los modos de vida, la conquista de la identidad personal, el derecho a ser uno mismo.

26. Ibíd., pp. 29-30.

27. Ibíd., pp. 77-78.

28. "El imperativo de la seducción queda manifiesto gracias a los presentadores jóvenes, atractivos, de voz y encanto tranquilizadores" LIPOVETSKI, G. (1991): El imperio de lo efímero. La moda y su destino en las sociedades modernas. Anagrama, Barcelona, p. 263.

29. La era del vacio, o. c., p. 106.

30. Ibíd., p. 109. 


\subsubsection{El cuerpo individualista y narcisista}

A cada generación le gusta reconocerse y encontrar su identidad en una figura mitológica o legendaria que reinterpreta y personifica los problemas y valores del momento. Hoy Narciso -sostiene Lipovetsky- es el símbolo de nuestro tiempo, al igual que en otro tiempo lo fueron Prometeo, Fausto o Sísifo... ${ }^{31}$. El narcisismo identifica la apariencia con el ser profundo y liga el problema de la expresión al de la autenticidad. Aparece así un nuevo aspecto del individualismo: un narcisismo que "designa el surgimiento de un perfil inédito del individuo en sus relaciones con él mismo y su cuerpo, con los demás, en el mundo y el tiempo, en el momento en que el 'capitalismo' autoritario cede paso al capitalismo hedonista y permisivo "32.

Este narcisismo es visible en múltiples prácticas cotidianas: angustia por la edad, obsesión por las arrugas, interés por la salud y la "línea"; rituales de control (chequeo) y mantenimiento (masajes, saunas, deportes, regímenes); cultos solares y terapéuticos: superconsumo de los cuidados médicos y productos farmacéuticos... Hemos de vigilar su buen funcionamiento, debemos respetarlo, es decir, vigilar constantemente su buen funcionamiento, combatir los signos de la degradación por medio de un reciclaje permanente quirúrgico, deportivo, dietético, etc. Se trata de un proceso de personalización que reclama la lucha contra la adversidad temporal, el combate por una identidad que hay que conservar sin interrupción: la juventud. Permanecer joven, no envejecer es el imperativo.

En tanto que persona, con estos cuidados el cuerpo ha ganado en beneficio de su identificación y dignidad como ser-sujeto. De este modo, el cuerpo ya no es una máquina, sino que designa nuestra identidad profunda de la que no cabe avergonzarse y que, por tanto, puede exhibirse desnudo en las playas y en los espectáculos, en su naturalidad.

Como todas las grandes dicotomías, la distinción entre el cuerpo y el espíritu se ha esfumado. La conciencia del cuerpo por sí mismo se ha convertido en una finalidad en sí para el narcisismo: hacer existir el cuerpo por sí mismo, estimular su autorreflexividad, conquistar la interioridad del cuerpo, ésa es la obra del narcisismo. El propio cuerpo se convierte en sujeto y, como tal, debe situarse en la órbita de la liberación, incluso de la revolución sexual, estética, dietética, sanitaria, etc. bajo la égida de "modelos directivos". El narcisismo cumple la función de normalización del cuerpo: el interés febril que tenemos por el cuerpo no es espontáneo y libre, obedece a imperativos sociales, tales como la "línea", la "forma", el orgasmo, etc. Así, la normalización postmoderna se presenta, una vez más, como el único medio de ser verdaderamente uno mismo, joven, esbelto, dinámico...

31. La era del vacio, p. 49.

"El narcisismo se ha convertido en uno de los temas centrales de la cultura americana" (p. 49). 'The Culture of Narcissism' de Chr. Lasch se ha convertido en un auténtico best-seller en todo el continente USA.

32. Ibíd., p. 50. 
Desde esta visión, es necesario liberar al cuerpo de los tabúes y sujeciones arcaicas y hacerlo permeable a las normas sociales, esa es la tarea del narcisismo. Paralelamente a la desustanciación del Yo, hay desustancialización del cuerpo, es decir, eliminación de la corporeidad salvaje o estática. El narcisismo, por la atención puntillosa hacia el cuerpo, por su preocupación permanente, desmonta la resistencia tradicional y hace al cuerpo disponible para cualquier experimentación. El cuerpo, como la conciencia, se convierte en un espacio flotante, un espacio deslocalizado, en manos de la "movilidad social".

El Narciso postmoderno, "demasiado absorto en sí mismo, renuncia a las militancias religiosas, abandona las grandes ortodoxias, sus adhesiones siguen la moda, son fluctuantes, sin mayor motivación. El laxismo sustituye al moralismo o puritanismo, y la indiferencia a la intolerancia"33. La personalización -a la que anteriormente hemos aludido- conlleva la carencia de conflictos, pues en los sistemas personalizados, los cismas y las herejías no tienen sentido, ya que al valorar el sentimiento subjetivo se desvalora el carácter objetivo de la acción. Ello pone en marcha la desustanciación de las acciones y doctrinas, que, al neutralizar sus contenidos, engendra una estrategia de desarme y oposición a todo dogmatismo.

Las relaciones sociales quedan fuertemente influidas en este narcisismo que, frecuentemente, adopta la visión de un individualismo insolidario, pues no es difícil convertir las relaciones humanas en relaciones de dominio, relaciones conflictivas basadas en la seducción fría y en la intimidación. "En nuestros sistemas narcisistas, cada uno corteja a sus superiores para obtener un ascenso, desea más ser envidiado que respetado y nuestra sociedad, indiferente al futuro, se presenta como una jungla burocrática donde reina la manipulación y la competencia de todos contra todos" 34 .

De este modo, el individualismo no destruye del todo las formas de participación en los combates colectivos, sino que modifica su carácter. Sería simplista reducir el individualismo contemporáneo al egocentrismo, al narcisista y a la sola búsqueda de placeres privados. El narcisismo es una tendencia dominante en las democracias, pero sin dirección exclusiva. Esporádicamente surgen luchas sociales, pero lejos de ser una oposición a la dinámica individualista, reproducen sus valores y características. Así, generalmente, los intereses particulares prevalecen sobre las consideraciones generales, la autonomía individual sobre la ortodoxia doctrinal, y el deseo inmediato de mejora sobre el sacrificio en beneficio de los demás ${ }^{35}$.

33. Ibíd., p. 67. "La sociedad hedonista sólo engendra a un nivel superficial la tolerancia y la indulgencia" (p. 73)

34. Ibíd., p. 68.

35. El imperio de lo efimero, o.c., p. 315. 


\subsubsection{El cuerpo estético}

El cuerpo en cuanto valor estético ("aisthetiké: sentir) adquiere en Lipovetsky, junto al sentido hedonista, un valor de belleza, de apariencia y de relación social. Ello hace que los valores imperantes como estéticamente sociales -la moda- gocen de un prestigio singular y hasta de un imperativo especial. De modo genérico, se asume como bello y bueno aquello que impera en un momento determinado y cuya posesión o vivencia nos caracteriza como vector de individualización narcisista, nos sitúa en un estatus social o nos identifica con un grupo determinado. Así, "la moda ha estetizado e individualizado la vanidad humana, ha conseguido hacer de lo superficial un instrumento de salvación, una finalidad de existencia ${ }^{36}$.

Gilles Lipovetsky, en "El imperio de lo efimero", título suficientemente significativo, dedicado a la moda, ésta es definida como "un sistema original de regulación y de presión social ${ }^{37}$. Hoy este sistema se nutre de paradojas e inconsistencias que tratan de relacionar lo efímero y la fantasía estética. Los rápidos cambios que esta presión conlleva, se convierten en un "deber" de adopción y asimilación, en un especial "despotismo" que irradia, junto a la coacción colectiva, un individualismo estético, así como un prestigio y rango. No hay moda sin prestigio y superioridad atribuidos a los nuevos modelos y, por tanto, sin cierto menosprecio por el orden antiguo.

No se trata de algo frívolo, como puede parecer, pues la moda es -más que algo que se explica a través de la sociedad- un estadio y una estructura de vida colectiva. No existe sociedad sin un fondo de ideas, sentimientos y deseos comunes ${ }^{38}$.

Nosotros nos limitamos aquí sólo a la estética del cuerpo manifestado en la moda, es decir, en unos cánones de belleza hoy socialmente vigentes, distintos, y a veces opuestos, a los precedentes. "Todo nuevo, todo bueno".

La representación social del cuerpo ha sufrido una mutación cuya profundidad puede compararse con el desmoronamiento democrático de la representación del prójimo. Conjuga mimetismo e individualismo, manifestándose con una mayor fuerza en el terreno de la apariencia: el modo de vestir, el peinado y el maquillaje son los signos más inmediatamente espectaculares de la afirmación del yo, el medio privilegiado de expresión de la unicidad de la persona, de la libertad individual, así como una forma de relación social ${ }^{39}$.

La estética del cuerpo se encuentra ligada al placer de ver y de ser mirado, de exhibirse a la mirada de los demás. No crea todas las piezas del narcisismo, sí lo reproduce de forma notable buscando la originalidad, la gracia, la creatividad, el placer de la vista, la diferencia y la seducción.

36. Ibíd., p. 42.

37. Ibíd., p. 42.

38. Ibíd., pp. 301-302

39. Ibíd., pp. 47-48. 
El traje, o modo de vestir, marca hoy lo mismo la igualdad que la diferencia entre masculino y femenino. Se trata de un proceso de igualación indumentaria que revela en seguida sus límites, para no anular las diferencias. Los hombres llevan el pelo largo y las mujeres visten prendas masculinas, existen almacenes unisex..., pero el corte de pelo es distinto, las blusas de las mujeres se distinguen de las de los hombres, la forma de los trajes de baño, los relojes y los paraguas... En cualquier caso, se sexualiza como nunca la apariencia acentuando las piernas, las caderas, los escotes, el pecho, los hombros... El vestido se convierte así en traje de seducción al acentuar los atractivos del cuerpo, revelando y ocultando los reclamos del sexo, avivando los encantos eróticos, fomentando la fantasía, el secreto y el misterio ${ }^{40}$.

Cuanto hemos indicado no se manifiesta en un único modo de vestir. Tales connotaciones se realizan de un modo plural, por lo que más que de moda -en singular- es necesario hablar de modas -en plural-. "Nos hallamos en la época de la proliferación y fragmentación de los cánones de la apariencia y de la yuxtaposición de los estilos más heteróclitos (...). Nada está prohibido, todos los estilos tienen carta de ciudadanía y se despliegan en orden diverso" ${ }^{41}$. De aquí que todos los estilos y todos los materiales cobran legitimidad como moda: el desaliño, lo sucio, lo desgarrado, lo descuidado, lo usado, lo deshilado y tantas cosas y aspectos hasta ahora excluidas: "jean" desteñido, zapatillas gastadas, grafismos de comics en las camisetas en tono de humor: Gutenberg en comic informal y disfrazado. Nos encontramos ante el "look mendigo" ${ }^{42}$. La gente ya no quiere ser elegante, quiere seducir, agradar, sorprender, confundir, romper con la tradición..., y sobre todo parecer joven, "estar en la onda". El culto a la juventud y al cuerpo avanzan al unísono, reclaman la misma atención constante hacia uno mismo, la misma vigilancia narcisista.

“Quién -se pregunta Lipovetski- no se empeña, de algún modo, en ofrecer una imagen joven y liberada de sí mismo, en adoptar, si no el último grito junior, sí al menos un aire, la 'gestalt joven? Incluso los adultos y las personas de edad se han pasado al sportswear, a los tejanos, a las camisetas, a las zapatillas deportivas y a los senos desnudos. Con esta promoción del estilo joven, el mimetismo se ha generalizado y se ha alejado de la fascinación que hasta ahora tenía el modelo aristocrático. El pasado tradicional deja de ser objeto de culto, el momento actual magnetiza las conciencias, se venera el cambio, el presente.

Hoy la moda adquiere connotación joven, frecuentemente parecida al mundo del trabajo: pantalón con peto, mono de pintor, chubasquero de marino, falda campesina, etc., lo frívolo se identifica con lo serio y lo funcional, la moda imita el mundo profesional. Al imitar la ropa utilitaria, la moda suaviza sus referencias,

40. Ibíd., pp. 72-73.

41. Ibíd., p. 139.

42. Ibíd., p. 35 y ss. 
debe expresar un estilo de vida emancipado, libre de obligaciones y de normas impuestas, inconformismo, humor e individualidad. Más aún que la perfección, preocupa la espontaneidad, originalidad, impacto inmediato o manifestar la ruptura con la generación precedente.

El individualismo contemporáneo reduce el símbolo jerárquico en favor del placer, la comodidad y la libertad. Hoy más que la admiración social, queremos seducir y estar cómodos, no tanto manifestar una posición social, cuanto mantener el gusto estético, y no tanto manifestar una posición de clase como parecer jóvenes y desenvueltos. En este contexto el fenómeno "jeans" merece particular atención; dado su "boom" en todas las clases y edades, su éxito, desde hace treinta años, hace que se haya convertido en el símbolo más característico de los gustos de moda en esta segunda parte del siglo XX.

La gran propaganda social del "jean" expresa la conjunción entre el individualismo y el conformismo, con una fuerte significación: es una prenda muy sufrida que puede llevarse en las más variadas circunstancias, que no exige planchado, ni limpieza meticulosa, una prenda que soporta desgastes, el deslavado y el desgarrón. Cargado intrínsecamente de una connotación antiinconformista, el "jean" fue adoptado en principio por los jóvenes, refractarios a las normas convencionales en vigor, pero contrarios a los nuevos valores hedonistas de las sociedades liberales dirigidas hacia el consumo. El rechazo de los códigos rigoristas y conformistas ha sido directamente ilustrado por la música rok y la ropa informal. El "jean» ha sido la manifestación de la cultura hiperindividualista fundada en el culto al cuerpo y a la búsqueda de la sensualidad. Lejos de ser uniforme, el ajean" subraya la forma del cuerpo y pone de relieve las caderas, la longitud de las piernas y las nalgas, y delinea cuanto hay de singular en la individualidad física. Es una prenda de resonancias táctiles y sexuales puesto de relieve en el arte moderno, en la literatura de vanguardia y en el rock. Con el "jean" la apariencia democrático-individual ha dado un nuevo salto hacia adelante para convertirse en la expresión de la individualidad desligada del estatus social ${ }^{43}$.

Así, la exaltación del look joven -nuevo foco de imitación social- mantiene vivo el valor del cuerpo, dando respuesta al hedonismo, fomentando el individualismo narcisista y fomentando la moda horizontal. En efecto, durante siglos, la difusión de la moda se produjo esencialmente a partir de la Corte y de la aristocracia, las capas inferiores copiaban los modales y atavíos de las cases superiores. Era la ley de propaganda imitativa de arriba abajo. Hoy se ha operado un cambio en este contagio imitativo: ya no imitamos lo superior, imitamos lo que vemos alrededor, los modos de vestir simples y graciosos. La ley de imitación vertical ha sido sustituida por una imitación horizontal en conformidad con una sociedad de individuos reconocidos como iguales ${ }^{44}$.

43. Ibíd., pp. 166-167.

44. Ibíd., p. 169. 
La denuncia de la moda -sostiene Lipovetsky- ha encontrado duras críticas por atentar contra la razón y ser una dictadura degradante de lo consumible, la infamia de las industrias culturales. Ya en los años cuarenta Adorno y Horkheimer se rebelaban contra la fusión monstruosa de la cultura de la publicidad y la diversión industrializada, que entrañaba la manipulación y estandarización de las conciencias. Más tarde Habermas analizará el listo-para-consumir mediático como instrumento de reducción de la capacidad de utilizar la razón de forma crítica. En cualquier caso, la crítica a la moda siempre estará ahí como consustancial a ella misma, una crítica que se puede calificar como quiera menos de accidental o superficial, pues en ella está siempre la reflexión filosófica entre las apariencias y el ser.

\subsubsection{El cuerpo indoloro, postmoralista o del postdeber}

Desde la Ilustración, los modernos han pretendido sentar las bases de una moral independiente de los dogmas religiosos: sin revelación, sin deberes absolutos, sin miedos y sin recompensas del más allá. Pero apenas lo han conseguido, pues "profesando el culto de las virtudes éticas, magnificando la obligación del sacrificio de la persona en el altar de la familia, la patria o la historia los modernos apenas han roto con la tradición moral de renuncia de sí que perpetúa el esquema religioso del imperativo ilimitado de los deberes ${ }^{45}$. Las obligaciones y deberes hacia Dios han sido transferidos a la esfera humana profana: hacia sí mismo, los otros o la colectividad. Pero en todo caso, el deber ha permanecido presente, sólo ha pasado de Dios al hombre, convirtiéndose en una "religión del deber laico" ${ }^{46}$.

Este período se ha cerrado. Desde hace aproximadamente medio siglo se ha puesto en marcha una nueva lógica de secularización de la moral, independiente de toda religión y de todo deber, por cuanto consiste en la disolución del deber mismo. Es la época del postdeber. En ésta, la sociedad "desvaloriza el ideal de abnegación estimulando sistemáticamente los deseos inmediatos, la pasión del ego, la felicidad intimista y materialista (...). Hemos dejado de reconocer la obligación de unirnos a algo que no sea nosotros mismos" ${ }^{47}$. De este modo, nos encontramos en la sociedad postmoralista en la que el deber está edulcorado y anémico, en la que la idea de sacrificio está socialmente deslegitimada, en la que la moral ya no exige consagrarse a un fin superior a uno mismo, en la que los derechos subjetivos dominan sobre los mandamientos imperativos, en la que las lecciones de moral están revestidas por los spots del vivir-mejor. En esta sociedad del postdeber el mal se hace espectáculo y los ideales se minimizan, persiste la condena de los vicios junto a la atonía del Bien. Los valores que reconocemos son más negativos (no hacer) que positivos ("tú debes"), detrás de la revitalización ética se da una moral indolora ${ }^{48}$.

45. LIPOVETSKY, G. (1996): El crepúsculo del deber. La ética indolora de los nuevos tiempos democráticos. Anagrama, Barcelona, p. 11.

46. Ibíd., p. 12.

47. Ibíd., p. 12.

48. Ibid., p. 48. 
Hemos pasado del Bien al bienestar. "Los goces del presente, el templo del yo, del cuerpo y de la comodidad se han convertido en la nueva Jerusalén de los tiempos posmoralistas" ${ }^{49}$. "Tras el imperativo categórico, el imperativo narcisista glorificado sin cesar por la cultura higiénica y deportiva, estética y dietética. Conservar la forma, luchar contra las arrugas, velar por una alimentación sana, broncearse, mantenerse delgado, relajarse, la felicidad individualista es inseparable de un extraordinario forcing del esfuerzo dinámico, mantenimiento, gestión óptima de uno mismo (...). Los nuevos imperativos son ahora: juventud, salud, esbeltez, forma, ocio, sexo " 50 .

El placer del cuerpo ya no está proscrito, sino masivamente valorado, promocionado, diversificado y liberado. El cuerpo es placer sexual, amor higienista, visión, relación, deporte, movilidad... El cuerpo es así objeto de libre disposición, no sujeto a normas morales preestablecidas. La estética ha sustituido a la ética y el placer ha sustituido a la ética. Así surge una nueva ética permisiva y hedonista en la que el esfuerzo ya no está de moda, todo lo que supone sujeción o disciplina austera se ha desvalorizado en beneficio del culto al deseo y de la realización inmediata ${ }^{51}$.

El sexo, desde hace medio siglo, ha dejado de ser asociado al mal. Hoy el "eros" se ha convertido en una de las expresiones más significativas del mundo del postdeber. "El sexo-pecado ha sido reemplazado por el sexo-placer. ¿Quién considera todavía la castidad y la virginidad como obligaciones morales? ¿Quién se indigna por la sexualidad libre de las mujeres y los jóvenes? ¿Quién pone en el Índice la masturbación? Incluso las desviaciones sexuales ya no son anatemizadas: se exhiben en la prensa y en los anuncios clasificados, los sadomasoquistas se expresan en los platós de televisión, en Dinamarca las parejas homosexuales son reconocidos por la ley, en Francia 3 de cada 4 jóvenes de entre 15 y 34 años no consideran condenable la homosexualidad,, 52 .

El movimiento de la liberación sexual afecta a todas las esferas de la vida, sin que existan deberes obligatorios que dirijan las conductas sexuales: consumo de masas sin limitaciones ni tabúes; desnudez sin clamores, ni indignaciones; moda y publicidad sexy, pornografía, mercado del cuerpo y propiedad de sí mismo... La fidelidad sigue siendo un valor, pero sólo durante algún tiempo, el tiempo que se ama.

Tales liberaciones, en modo alguno equivale a un estado de jungla, es más, la liberación ha restablecido un nuevo equilibrio erótico colectivo, pues "cuantas más libertades sexuales hay, menos predominantes son socialmente los excesos libidinales (...). Los modelos son múltiples, sin dirección obligada; sólo queda la exigencia del acuerdo de uno consigo mismo, las compatibilidades o incompatibilidades de las personas y los deseos ${ }^{53}$. Así, el postdeber sólo aspira a la ampliación

49. Ibíd., p. 50.

50. Ibíd., p. 55.

51. La era del vacio, o. c., p. 56 y ss.

52. Ibíd., p. 38.

53. Ibíd., p. 63. "A pesar del proceso de liberación de las costumbres, cierto número de comportamientos sexuales siguen condenados: incesto, perversión de menores, prostitución, actos de zoofilia, sadomasoquismo..." (p. 60). 
de los derechos individuales, sin laxismo ni espiral diabólica de los derechos subjetivos, por lo que "lejos de pacificar el debate ético, la cultura fuera-del-deber lo agudiza, lo lleva a nivel de masas, ahonda el antagonismo de las perspectivas „54.

Para concluir, nada más significativo que las siguientes palabra de Lipovetsky referidas a la importancia actual del cuerpo: "Jamás el cuerpo ha sido tan gran objeto de atención, de trabajo, de protección y de reparación" "55.

\subsubsection{La calle o postmodernidad popular}

Cuanto anteriormente hemos indicado -siguiendo el pensamiento de Lipovetsky o al menos buena parte de él- posee su prolongación en la calle, es decir, fuera de las aulas y del pensamiento filosófico. A ello hemos denominado "postmodernidad popular". Por supuesto que no a toda la sociedad cabe aplicarle el calificativo de "postmoderna", pero sí múltiples de los valores de la postmodernidad, y en consecuencia del cuerpo, se encuentran presentes en los actuales medios de comunicación social. Vivimos en una fuerte cultura del cuerpo.

Los "mass-media", en cada momento, reflejan la realidad social; explican, crean y reproducen valorativamente patrones de conducta y estilos de vida, transmiten saberes, valores, patrones de conducta, ideales, etc. Ellos hoy lo exhiben todo o casi todo, pero juzgan poco.

Hoy el mundo de la imagen, y singularmente la TV, goza de un atractivo especial. Las generaciones jóvenes son cada vez menos lectoras y cada día más televisivas. La fuerza seductora de la TV reside en que su comunicación se realiza desde el marco del placer, de la renovación y de la distracción. Todas sus emisiones deben adoptar la perspectiva del ocio. El objetivo fundamental es "enganchar" a la mayor parte del público mediante la tecnología del ritmo rápido y placentero. Seducir es lo primero. Baste observar los presentadores/as de informativos, concursos y sobre todo publicidad: jóvenes, sexy, simpáticos, atractivos, encantadores, de voz tranquilizadora, etc.

De este modo, los medios de comunicación son "medios privilegiados" de creación y transmisión de valores y por tanto, de innovación, cambio o potenciación de una determinada cultura y mentalidad. Valores, por ejemplo, como el esfuerzo, el sacrificio, el ahorro, la autoridad o la castidad -como escribe Lipovetsky- ya no inspiran respeto, e invitan más a la sonrisa que a la veneración ${ }^{56}$. Su lugar lo ocuparán hoy, para no pocas personas, el individualismo hedonista y narcisista, el esteticismo, el relativismo, el humorismo frente al realismo, el consumo, la inmediatez,

54. Ibíd., p. 13. El tema del orden moral está en boga, pero ¿de qué moral se habla exactamente? Nuestra época no restablece el reino de la "antigua buena moral" sino que se libera de ella (p. 10).

55. Ibíd., p: 102.

56. LIPOVETSKY, G., La era del vacío, o.c., p. 162. 
la liberación de toda atadura... El derecho, en definitiva, a ser uno mismo y a disfrutar al máximo la vida.

En prensa, radio y TV, hoy encontramos un modelo estético de cuerpo cuyos valores residen en la altura, delgadez, piel morena, juventud, pelo largo... Su vestido es desenfadado, de fuertes colores vivos y combinados e imitando el mundo del trabajo: pantalones y cazadoras vaqueros, a veces, rotos y parcheados, zapatillas, botas, etc. Es necesario aparentar dinamismo, belleza, deportividad, ser sexy y atractivo, rico y actual. El cuerpo es no sólo algo que tenemos, sino lo que somos; un instrumento u objeto de placer, lo que, en un primer momento, nos identifica y nos facilita o entorpece la relación con los demás: "pasteleo" y "ligues", fiestas, amigos, posición social y, en ocasiones, hasta trabajo. De ahí que, en una sociedad en la que predomina la apariencia sobre el ser, el cuidado, cultivo, y hasta "culto" al cuerpo ocupen lugares privilegiados.

Las manifestaciones de este modo de entender y dar sentido al cuerpo son visibles en nuestra vida social y en todos los grandes medios de comunicación. Revista, vallas, periódicos, radio y TV nos ofrecen spots publicitarios, invitando y prometiendo:

- Dietas de adelgazamiento, en escaso tiempo y sin esfuerzo, que puede llegar hasta la anorexia.

- Productos eficaces contra la caída del cabello, las canas, las arrugas o para fomentar el moreno de la piel.

- Gimnasios, academias, centros de estética y salones de belleza hoy se multiplican para ofrecernos múltiples servicios: manicura, cera fría y caliente, maquillajes, limpieza de cutis, masajes corporales, tratamientos faciales y corporales, body fitness (aparatos, gimnasia de mantenimiento, aerobic, stretching), body building (culturismo de competición y para aficionados, masculino y femenino), saunas, gim-jazz, etc.

- Productos "light, bajos en calorías: Coca cola, cerveza, quesos, mahonesas, leches desnatadas... que conservan su sabor, pero no engordan.

- Múltiples formas de belleza, de conservar la línea. Piénsese en la cirugía estética, en el número de personas que encontramos haciendo "footin" en los parques o calles de nuestras ciudades, con la obsesión por no engordar, de no envejecer. La vejez -antes sinónimo de experiencia, autoridad, sabiduría- ha perdido todo su valor, para convertirse casi en "desgracia". Hoy hasta el mismo nombre se sustituye por el de "tercera edad".

- Modos de gozar sexualmente. El cuerpo ya no es algo negativo, y menos aún el enemigo que es necesario combatir. Es nuestra identidad profunda, medio y fin de gozo y placer, de la que no cabe avergonzarse. Por eso, se exhibe desnudo o semidesnudo en playas, revistas y espectáculos, constituyendo su desnudez, y sobre todo la sexualidad, momentos y motivo de placer. El cine y revistas porno, la línea 906 del teléfono erótico, internet, las salas X, los sex-shop, el strip-tease, las escenas eróticas, (presentes hoy 
en la mayoría de las películas y concursos de TV) y hasta su mismo vocabulario, son datos que hablan por sí mismos.

- Productos que nada tienen que ver con el atractivo del cuerpo, pero que se valen de éste para su venta y difusión. Es un modo, hoy muy generalizado, de captar la atención en programas y anuncios. Señoritas atrayentes sobre el capó de un coche, caricias y besos para presentar un perfume o bebida, etc.

Otro tanto cabe decir de la moda. Hoy, acorde con los nuevos valores, la moda adquiere connotación joven, debe expresar un estilo de vida emancipado, libre de obligaciones y de normas impuestas, inconformismo, humor e individualidad. Más aún que la perfección, preocupa la espontaneidad, originalidad, impacto inmediato o manifestar la ruptura con la generación precedente. Antes las hijas deseaban parecerse a sus madres, actualmente sucede todo lo contrario. Representar menos edad importa hoy mucho más que exhibir un rango social. De aquí la extensión de los vaqueros, las camisetas, las zapatillas deportivas, o los colores vivos, etc. Es la exaltación del nuevo look joven -nuevo foco de imitación social- que mantiene vivo el valor del cuerpo.

Los medios de comunicación, en el sentido indicado y de modo permanente, nos crean necesidades ofreciéndonos, en cantidad y variedad, toda clase de productos de caducidad acelerada. Su poder de seducción es tal que se hace difícil resistir a su fuerza, pues en un mismo mensaje, directa o indirectamente, junto al bienestar y utilidad del producto, se ofrece también la distinción y pertenencia a un status social superior. De este modo, más o menos conscientemente, el consumismo nos conduce a un materialismo hedonista y narcisista sin límites, en el que tener, gozar y aparentar, vale mucho más que el ser.

En síntesis, pues, el cuerpo, desde el relativismo y la estetización general de la vida, es un elemento fruitivo de goce y belleza. Algo que, junto al placer de ser $y$ tener propios, nos facilita la relación social, nos cataloga en un status determinado, y hasta nos abre las puertas al mundo laboral. Ello hace que el deseo de gustar, el acceso al otro sexo y al grupo de amigos, encuentre en el cuerpo un medio $\mathrm{y}$ valor tan fuertes que ha llegado a convertirlo en un verdadero "culto".

\section{LA EDUCACIÓN DEL CUERPO EN EL DESAFÍO POSTMODERNIDAD-CRISTIANISMO}

Esta pluralidad axiológica, proclamada y fomentada por todos como riqueza de la vida social, se torna frecuentemente en pluralidad problemática en el mundo de la educación. Vivimos en una sociedad de tantos valores, $\mathrm{y}$, a veces, en abierta oposición, que se hace difícil, cuando no imposible, distinguir el valor del antivalor. La convivencia frecuentemente se convierte en abierta competencia.

Por una parte, en la educación religiosa (catequesis o enseñanza religiosa escolar), al niño y al joven se les sitúan en el camino -currículo educativo- cuya meta final, en el tema que nos ocupa, es la consecución de un cuerpo cuyos sentidos nos vienen dados por los siguientes valores: 
1. En cuanto al cuerpo-sexo han de darse conjuntamente:

- sexo con amor y éste estable,

- sexo siempre abierto a la procreación,

- matrimonio canónico.

En consecuencia es rechazada la masturbación, las relaciones prematrimoniales, los preservativos y anticonceptivos, la prostitución, inseminación artificial, homosexualidad, etc.

2. En cuanto al cuerpo-estético, se orienta hacia:

- el ser más que el aparecer,

- la indiferencia ante la moda,

- la superioridad de la dimensión ética del cuerpo sobre la estética.

3. En cuanto al cuerpo-hedonismo-narcisismo:

- placer subordinado a otros valores,

- austeridad y moderación,

- sacrificio, la ascesis y la lucha.

Junto a estos valores transmitidos en la educación formal o no formal (educación religiosa escolar o catequesis), la educación informal-postmodernidad intelectual (Lipovetsky), así como su prolongación en la calle- transmite frecuentemente, a través de distintos medios, un cuerpo entendido como valioso:

\section{En cuanto al cuerpo-sexo:}

- práctica sexual sin condicionamiento alguno de amor o sentimiento,

- la unión sexual no necesariamente abierta a la procreación,

- las reacciones no están condicionadas por el matrimonio.

2. En cuanto al cuerpo-estético:

- predomino de la estética sobre la ética,

- superior valoración del aparecer ("look") sobre el ser,

- importancia de la moda.

3. En cuanto al cuerpo-bedonista-narcisista:

- el placer libre de toda atadura moral y costumbre social,

- el "yo" como punto central de referencia,

- renuncia a la ascética y militancia esforzada política o religiosa.

De este modo, nos encontramos ante un antagonismo o pluralidad problemática, que nosotros hemos denominado "desafío" -en el sentido que le otorga la Real Academia Española de la Lengua- de provocación, de rivalidad, de batalla, entre los valores religiosos existentes durante siglos entre nosotros y el reto de los nuevos valores postmodernos emergentes.

En opinión de Giani Vattimo esta situación es irreconciliable: "La Europa moderna, la occidental y su modo de vida son profundamente irreconciliables con la esencia del cristianismo. Occidente es sinónimo de consumismo, hedonismo y pluralismo babélico". Diagnóstico en el que coincide también el Papa Juan Pablo II 
-bajo el término "neopaganismo", que hace Dios al hombre o prescinde de Diospero admitiendo la posibilidad de reconciliación y, por tanto, la propuesta de una "nueva evangelización" 57 .

El Curso sobre "Familia y MCS", celebrado en El Escorial (24-28 julio, 1996), hacía patente este mismo problema, por lo que una de sus conclusiones afirmaba lo siguiente: "Los conflictos que pueden producirse entre los legítimos derechos democráticos, como el de la libertad de expresión de los medios de comunicación y el de los padres a educar a sus hijos, debe resolverse por cauces de diálogo y entendimiento". En su comunicado lamentan que los medios de comunicación se conviertan en una escuela paralela, que impone valores, formas y estilos de vida que deseducan, perjudican y dirigen a los adolescentes y jóvenes en contra de lo que una gran mayoría de los padres quieren para sus hijos. Una escuela, añaden, ante la que muchos padres no pueden contra el ambiente creado por una reiterada lluvia de mensajes que menoscaba su labor, por más cuidadosa y generosa que sea ${ }^{58}$.

La educación como "praxis" es siempre acción orientada hacia el valor, pues no es posible educar sin teleología. En teoría la solución es fácil: opción por los valores cristianos del cuerpo (catequesis, educación religiosa escolar) o por los valores de la postmodernidad (educación informal y no formal). El problema en este tema radica en que no es fácil desoír la opción contraria, pues los medios de comunicación, en sus diversas modalidades, se hacen permanentemente presentes en nuestra vida. En ellos, de modo bastante generalizado, el cuerpo muestra los valores de la postmodernidad. Es una invitación constante a su vivencia.

¿Qué hacer cuando dos valores distintos, y en nuestro caso en abierta oposición, reclaman nuestra atención y orientación? No hay otra posibilidad que la opción. Una opción que, en la educación, se convierte en decisión ( "decido": determinar, resolver) precedida de deliberación y volición (acto de la voluntad). Lo que Aristóteles y los escolásticos denominaron elección, es decir, el momento final de la deliberación en el cual se determina o resuelve el compromiso hacia una de las alternativas posibles.

La decisión, por tanto, no es algo espontáneo, ni a ciegas, sino que va precedida de la deliberación: un conocimiento y reflexión de las alternativas posibles en la situación presente, tras la cual la voluntad decide como principio racional de la acción. "Apetencia voluntaria de las cosas que dependen de nosotros" como ya afirmó Aristóteles ${ }^{59}$. El acto, por tanto, de decisión, (el querer, esencia de la voluntad) está unido a un juicio de valor en el que lo intelectual y lo afectivo forman parte de un todo. A diferencia del animal que no prefiere, el hombre se halla 'sobre

57. VATTIMO, G. (1993) Coloquio celebrado en Barcelona sobre el tema "Pensar Europa", en Vida Nueva, $\mathrm{n}^{\mathrm{o}} 1881,13$ de febrero, p. 39.

58. Vida Nueva, $\mathrm{n}^{\mathrm{Q}} 2.052,3$ agosto, 1996, p. 15. Los padres proponen como solución un diálogo razonado con los hijos y una presencia pública de asociaciones y movimientos familiares en los medios de comunicación.

59. Étic. Nic., III, 3, 1113a 10. 
sí mismo', es decir, querer realizarse en algo que quiere. Lo que el hombre quiere es un elemento integrante de su propia realización.

Ello, en el tema que nos ocupa, no es nada fácil, por cuanto los diversos ámbitos educativos ejercen su fuerza en un mismo sujeto, viéndose éste sometido a fuerzas y valores antagónicos. Y si toda decisión es en sí conflictiva, aquí lo es aún más por los problemas añadidos que conlleva nuestra sociedad. He aquí algunos:

1. La valoración unilateral que, ante cualquier tema, realizan los medios de comunicación social: prensa, radio o televisión. Nuca hemos sabido tanto de tantas cosas, pero también nunca hemos ignorado tanto de tantas cosas. El acceso a los múltiples rostros de una misma realidad se hace difícil, o acaso imposible, al hombre de hoy.

2. La inmadurez psicológica de quienes se educan, en nuestro caso fundamentalmente niños, jóvenes y adolescentes. Tales destinatarios se encuentran a veces incapacitados, y en otras ocasiones con grandes dificultades, para tomar decisiones en el sentido educativo ya indicado. Frecuentemente son los padres, los amigos, o el líder en turno, o bien la moda, quienes deciden, por lo que la falta de deliberación es manifiesta.

3. La fuerza de la Escuela Paralela. ( Non scholae sed vitae discimus"). Hoy la educación oficial o formal ha perdido fuerza en favor de la educación no formal y, sobre todo, informal. Ésta goza hoy de un mayor poder y atractivo para inculcar valores que las clases y los textos escolares, su fuerza se manifiesta con toda virulencia, sobre todo, en los jóvenes. El ambiente: la $\mathrm{TV}$, las revistas, novelas, calle, canciones, etc. poseen una mayor energía formativa que los educadores. Así, la Escuela Paralela coexiste, con ventaja, sobre la escuela oficial, la educación religiosa con los valores de la Postmodernidad.

Ante esta coexistencia plural y antagónica, el desafío postmoderno actúa con ventaja, pues se trata del desafío del placer al esfuerzo, de lo estético a lo ético, de la apariencia al ser, del bien al bienestar, de la moral del deber al deber indoloro... Y ello, además, en un ambiente genéricamente favorecedor del desafío postmoderno. El éxito parece, pues, bastante generalizado.

\section{ALGUNAS ORIENTACIONES EDUCATIVAS}

Ante esta situación, más o menos vigente según ámbitos y edades, la pregunta de no pocos educadores es qué hacer, por cuanto la opción es irrenunciable. A modo de tesis enumeramos las siguientes orientaciones, que también son conclusiones:

1. El cuerpo posee múltiples caras o valoraciones que es necesario precisar en la educación para no incurrir en la ambigüedad del lenguaje que conduce a la confusión comunicativa, situación ésta propicia para la manipulación. 
EL CUERPO COMO VALOR EDUCATIVO: LA POSTMODERNIDAD FRENTE AL CRISTIANISMO

2. La misión del educador de ayuda al educando en la búsqueda del valorcuerpo ha de realizarse mediante la deliberación (reflexión y valoración), paso previo de la decisión.

3. Ni educador ni educando deben olvidar que la educación es una conquista personal, una lucha, o mejor una carrera ("currículum") cuya consecución es inseparable del esfuerzo personal, pero también inseparable del agrado o ilusión.

El error, a nuestro entender, radica en la identificación placer-valor que, si bien en ocasiones son coincidentes, en otros momentos se presentan en abierta oposición. La opción por el valor exige, a veces, esfuerzo, más aún en las sociedades desarrolladas en las que la técnica ha contribuido poderosamente a que gocemos de "la aventura del sillón". Hoy, quizás más que nunca, la educación es una meta esforzada, cuyo camino está lleno de placeres que, a veces, hemos de saber sortear para lograr el deber-ser del valor cuerpo.

\section{BIBLIOGRAFÍA}

COLOM, J. (1981): Manual de catequesis. Herder. Barcelona.

GERVILLA, E. (1990): La Escuela del Nacional-Catolicismo. Ideología y Educación Religiosa. Impredisur, Granada.

- (1993): Postmodernidad y Educación. Valores y Cultura de los Jóvenes, Dykinson. Madrid.

- (1999): Valores del cuerpo educando. Antropología del cuerpo y educación. Herder. Barcelona.

LIPOVETSKY, G. (1990): La era del vacío. (Ensayos sobre el individualismo contemporáneo). Anagrama. Barcelona.

- (1991): El imperio de lo efimero. (La moda y su destino en las sociedades modernas). Anagrama. Barcelona.

- (1996): El crepúsculo del deber. (La ética indolora de los nuevos tiempos democráticos). Anagrama. Barcelona.

RUBIO CARRACEDO, J. (1966): Educación moral, postmodernidad y democracia. Trotta. Madrid.

RUIZ DE LA PEÑA, J. L. (1988): Imagen de Dios. Antropología teológica fundamental. Sal Terrae. Santander. 